\title{
Chemotherapy for Biliary Tract Cancer in 2021
}

\author{
Takashi Sasaki *(D), Tsuyoshi Takeda ${ }^{\mathbb{D}}$, Takeshi Okamoto, Masato Ozaka and Naoki Sasahira
}

Citation: Sasaki, T.; Takeda, T.; Okamoto, T.; Ozaka, M.; Sasahira, N. Chemotherapy for Biliary Tract Cancer in 2021. J. Clin. Med. 2021, 10, 3108. https://doi.org/10.3390/ jcm10143108

Academic Editor: Stanley W. Ashley

Received: 18 June 2021

Accepted: 13 July 2021

Published: 14 July 2021

Publisher's Note: MDPI stays neutral with regard to jurisdictional claims in published maps and institutional affiliations.

Copyright: (c) 2021 by the authors. Licensee MDPI, Basel, Switzerland. This article is an open access article distributed under the terms and conditions of the Creative Commons Attribution (CC BY) license (https:// creativecommons.org/licenses/by/ $4.0 /)$.
Department of Hepato-Biliary-Pancreatic Medicine, Cancer Institute Hospital of Japanese Foundation for Cancer Research, 3-8-31, Ariake, Koto-ku, Tokyo 135-8550, Japan; tsuyoshi.takeda@jfcr.or.jp (T.T.); takeshi.okamoto@jfcr.or.jp (T.O.); masato.ozaka@jfcr.or.jp (M.O.); naoki.sasahira@jfcr.or.jp (N.S.)

* Correspondence: sasakit-tky@umin.ac.jp; Tel.: +81-3-3520-0111; Fax: +81-3-3520-0141

\begin{abstract}
Biliary tract cancer refers to a group of malignancies including cholangiocarcinoma, gallbladder cancer, and ampullary cancer. While surgical resection is considered the only curative treatment, postoperative recurrence can sometimes occur. Adjuvant chemotherapy is used to prolong prognosis in some cases. Many unresectable cases are also treated with chemotherapy. Therefore, systemic chemotherapy is widely introduced for the treatment of biliary tract cancer. Evidence on chemotherapy for biliary tract cancer is recently on the increase. Combination chemotherapy with gemcitabine and cisplatin is currently the standard of care for first-line chemotherapy in advanced cases. Recently, FOLFOX also demonstrated efficacy as a second-line treatment. In addition, efficacies of isocitrate dehydrogenase inhibitors and fibroblast growth factor receptor inhibitors have been shown. In the adjuvant setting, capecitabine monotherapy has become the standard of care in Western countries. In addition to conventional cytotoxic agents, molecular-targeted agents and immunotherapy have been evaluated in multiple clinical trials. Genetic testing is used to check for genetic alterations and molecular-targeted agents and immunotherapy are introduced based on tumor characteristics. In this article, we review the latest evidence of chemotherapy for biliary tract cancer.
\end{abstract}

Keywords: biliary tract cancer; cholangiocarcinoma; chemotherapy; cytotoxic agents; molecular targeted agents; immunotherapy; precision medicine; genetic testing

\section{Introduction}

Biliary tract cancer is a heterogeneous group of highly aggressive cancers including intrahepatic/perihilar/distal cholangiocarcinoma, gallbladder cancer, and ampullary cancer [1]. Biliary tract cancer is common in Japan, Southeast Asia, South America, and India [2,3]. Cholangiocarcinoma has been increasing worldwide, while the incidence of gallbladder cancer has been decreasing in recent years [4-6]. In Japan, the incidence and mortality of biliary tract cancer have plateaued over the last decade, with an annual incidence and mortality of approximately 22,000 and 18,000, respectively [7]. This cancer is still the sixth leading cause of cancer-related death. In Japan, more than $45 \%$ of new cases are diagnosed over the age of 80 .

While surgical resection is considered the only curative treatment, postoperative recurrence can sometimes occur. Data from the biliary tract cancer registry in Japan revealed that five-year survival rates were 39.8\% for gallbladder cancer, $24.2 \%$ for perihilar cholangiocarcinoma, 39.1\% for distal cholangiocarcinoma, and 61.3\% for ampullary cancer [8]. Adjuvant chemotherapy is sometimes introduced to achieve long-term survival for resected cases with poor prognostic factors. Many unresectable cases are also treated with chemotherapy. As surgery for biliary tract cancer is a highly invasive procedure, surgery may be avoided in potentially resectable cases due to old age or comorbidities. Therefore, systemic chemotherapy is widely introduced for the treatment of biliary tract cancer. Recently, evidence on chemotherapy for biliary tract cancer is on the increase. In addition to conventional cytotoxic agents, molecular-targeted agents and immunotherapy 
have widely been introduced in this field. Genetic testing is used to check for genetic alterations and molecular-targeted agents and immunotherapy are introduced based on tumor characteristics. Here, we review the latest evidence on chemotherapy for biliary tract cancer.

\section{First-Line Chemotherapy for Advanced Biliary Tract Cancer}

Standard chemotherapy for biliary tract cancer was not established until about 2000. Until then, chemotherapy for pancreatic cancer had been used as a reference. The efficacy of chemotherapy was confirmed in a randomized control study conducted before 2000 which compared chemotherapy to best supportive care in advanced pancreatic and biliary tract cancers [9]. Subsequently, a randomized controlled study comparing chemotherapy and best supportive care for unresectable gallbladder cancer was reported from India in 2010, confirming the usefulness of chemotherapy [10]. Between 2000 and 2010, gemcitabine and 5-fluorouracil were considered the key drugs for the treatment of advanced cases. A pooled analysis of clinical trials conducted between 1985 and 2006 identified gemcitabine, fluoropyrimidines, and cisplatin as the key active agents and concluded that gemcitabine combined with platinum compounds represented the provisional standard of chemotherapy for advanced biliary tract cancer [11].

The combination chemotherapy of gemcitabine and platinum compounds demonstrated good efficacy in advanced cases. A randomized phase II study (ABC-01) comparing the doublet of gemcitabine and cisplatin to gemcitabine alone was reported from the United Kingdom [12]. The doublet regimen was associated with improved tumor control and progression-free survival. Based on this result, the study was extended to a phase III study (ABC-02) to verify the prognostic effect of the combination chemotherapy relative to gemcitabine monotherapy [13]. Four hundred ten patients were randomized to receive either gemcitabine and cisplatin combination chemotherapy or gemcitabine alone. The primary endpoint was overall survival. The median overall survival was 11.7 months in the combination group and 8.1 months in the monotherapy group (hazard ratio, 0.64 ; $p<0.001)$. The median progression-free survivals of the combination and monotherapy groups were 8.0 months and 5.0 months, respectively $(p<0.001)$. The rate of tumor control among patients in the combination group was significantly increased $(81.4 \% \mathrm{vs} .71 .8 \%$, $p=0.049)$. Although neutropenia occurred more frequently in the combination group, combination chemotherapy with gemcitabine and cisplatin was considered a feasible regimen for advanced biliary tract cancer. This combination chemotherapy was also evaluated in Japanese patients and similar efficacy was confirmed in a multicenter, randomized phase II study (BT-22) [14]. Treatment was repeated for up to 24 weeks in the ABC-02 study and up to 48 weeks in the BT-22 study. In a meta-analysis of these two studies, the efficacy of gemcitabine and cisplatin combination chemotherapy was confirmed in patients with good performance status (performance status of 0 or 1 ) and in patients with cholangiocarcinoma or gallbladder cancer [15]. On the other hand, the superiority of this combination chemotherapy was not shown in patients with poor performance status or ampullary cancer. The major grade $3 / 4$ adverse events of gemcitabine and cisplatin combination chemotherapy were neutropenia and anemia. We also need to pay attention to renal dysfunction and hearing loss. Oxaliplatin is another platinum compound known to cause less renal damage and therefore does not require aggressive hydration, unlike cisplatin. Oxaliplatin is sometimes used as a substitute for cisplatin. However, the noninferiority of gemcitabine and oxaliplatin combination chemotherapy, when compared to gemcitabine and cisplatin combination chemotherapy, has not been proven. One randomized controlled study comparing these two regimens was conducted in India [16]. A total of 243 patients with unresectable gallbladder cancer were randomly assigned to one of these two regimens. The median overall survivals of gemcitabine and oxaliplatin combination chemotherapy and gemcitabine and cisplatin combination chemotherapy were 9.0 months and 8.3 months, respectively (hazard ratio, $0.78 ; p=0.057$ ). Because the predetermined statistical threshold was not met, the study failed to prove non-inferiority. 
Moreover, this study was underpowered to determine the superiority of gemcitabine and oxaliplatin combination chemotherapy.

Several randomized controlled studies have been conducted in pursuit of treatment regimens that are superior to the standard treatment of gemcitabine and platinum compounds. Some involved combination chemotherapies which added a third drug to the doublet, while others involved a novel regimen. Table 1 summarizes previous randomized controlled studies on first-line chemotherapy for advanced biliary tract cancer. No additional benefits of epidermal growth factor receptor and vascular endothelial growth factor receptor inhibitors have been observed to date [17]. On the other hand, good results have been obtained with S-1, which is widely used in Japan [18,19].

Table 1. Randomized controlled studies on first-line chemotherapy for advanced biliary tract cancer.

\begin{tabular}{|c|c|c|c|c|c|c|c|c|}
\hline Authors & Year & Regimen & Phase & Result & $\mathbf{N}$ & RR & Median PFS & Median OS \\
\hline \multirow{2}{*}{$\begin{array}{c}\text { Valle } \\
\text { et al. [13] }\end{array}$} & \multirow{2}{*}{2010} & GemCis & \multirow{2}{*}{3} & \multirow{2}{*}{ Positive } & 204 & $26.1 \%$ & $8.0 \mathrm{M}$ & $11.7 \mathrm{M}$ \\
\hline & & GEM & & & 206 & $15.5 \%$ & $5.0 \mathrm{M}$ & $8.1 \mathrm{M}$ \\
\hline \multirow{3}{*}{$\begin{array}{l}\text { Sharma } \\
\text { et al. [10] }\end{array}$} & \multirow{3}{*}{2010} & GEMOX & \multirow{3}{*}{3} & \multirow{3}{*}{ Positive } & 26 & $30.7 \%$ & $8.5 \mathrm{M}$ & $9.5 \mathrm{M}$ \\
\hline & & $5 \mathrm{FU}+\mathrm{FA}$ & & & 28 & $14.3 \%$ & $3.5 \mathrm{M}$ & $4.6 \mathrm{M}$ \\
\hline & & BSC & & & 27 & $0 \%$ & $2.8 \mathrm{M}$ & $4.5 \mathrm{M}$ \\
\hline \multirow{2}{*}{$\begin{array}{l}\text { Lee } \\
\text { et al. [17] }\end{array}$} & \multirow{2}{*}{2012} & GEMOX + & \multirow{2}{*}{3} & \multirow{2}{*}{ Negative } & 135 & $29.6 \%$ & $5.8 \mathrm{M}$ & $9.5 \mathrm{M}$ \\
\hline & & GEMOX & & & 133 & $15.8 \%$ & $4.2 \mathrm{M}$ & $9.5 \mathrm{M}$ \\
\hline \multirow{2}{*}{$\begin{array}{l}\text { Sharma } \\
\text { et al. [16] }\end{array}$} & \multirow{2}{*}{2019} & GEMOX & \multirow{2}{*}{3} & \multirow{2}{*}{ Negative } & 119 & $25.2 \%$ & $5.0 \mathrm{M}$ & $9.0 \mathrm{M}$ \\
\hline & & GemCis & & & 124 & $23.4 \%$ & $4.0 \mathrm{M}$ & $8.3 \mathrm{M}$ \\
\hline \multirow{2}{*}{$\begin{array}{l}\text { Morizane } \\
\text { et al. [18] }\end{array}$} & \multirow{2}{*}{2019} & GEM + S-1 & \multirow{2}{*}{3} & \multirow{2}{*}{ Positive } & 179 & $29.8 \%$ & $6.8 \mathrm{M}$ & $15.1 \mathrm{M}$ \\
\hline & & GemCis & & & 175 & $32.4 \%$ & $5.8 \mathrm{M}$ & $13.4 \mathrm{M}$ \\
\hline \multirow{2}{*}{$\begin{array}{c}\text { Sakai } \\
\text { et al. [19] }\end{array}$} & \multirow{2}{*}{2018} & $\underset{\text { S-1 }}{\text { GemCis + }}$ & \multirow{2}{*}{3} & \multirow{2}{*}{ Positive } & 123 & $41.5 \%$ & $7.4 \mathrm{M}$ & $13.5 \mathrm{M}$ \\
\hline & & GemCis & & & 123 & $15.0 \%$ & $5.5 \mathrm{M}$ & $12.6 \mathrm{M}$ \\
\hline \multirow{2}{*}{$\begin{array}{c}\text { Kim } \\
\text { et al. [20] }\end{array}$} & \multirow{2}{*}{2019} & $\begin{array}{c}\text { Cape + } \\
\text { Oxaliplatin }\end{array}$ & \multirow{2}{*}{3} & \multirow{2}{*}{ Positive } & 108 & $15.7 \%$ & $5.8 \mathrm{M}$ & $10.6 \mathrm{M}$ \\
\hline & & GEMOX & & & 114 & $24.6 \%$ & $5.3 \mathrm{M}$ & $10.4 \mathrm{M}$ \\
\hline Phelip & & mFOLFIRINOX & & Negative & 94 & $25.0 \%$ & $6.2 \mathrm{M}$ & $11.7 \mathrm{M}$ \\
\hline et al. [21] & 2020 & GemCis & $2 / 3$ & Negative & 96 & $19.4 \%$ & $7.4 \mathrm{M}$ & $14.3 \mathrm{M}$ \\
\hline Kang & & $\mathrm{S}-1+\mathrm{CDDP}$ & & & 47 & $23.8 \%$ & $5.4 \mathrm{M}$ & $9.9 \mathrm{M}$ \\
\hline et al. [22] & 2012 & GemCis & rP2 & Positive & 49 & $19.6 \%$ & $5.7 \mathrm{M}$ & $10.1 \mathrm{M}$ \\
\hline Lee & 2015 & $\begin{array}{l}\text { Cape + } \\
\text { CDDP }\end{array}$ & rP2 & Positive & 44 & $27.3 \%$ & $5.2 \mathrm{M}$ & $10.7 \mathrm{M}$ \\
\hline & & GemCis & & t & 49 & $6.1 \%$ & $3.6 \mathrm{M}$ & $8.6 \mathrm{M}$ \\
\hline Malka & 2014 & $\begin{array}{c}\text { GEMOX + } \\
\text { Cmab }\end{array}$ & rP2 & Negative & 76 & $23.1 \%$ & $6.0 \mathrm{M}$ & $11.0 \mathrm{M}$ \\
\hline et al. [24] & & GEMOX & & & 74 & $29.0 \%$ & $5.3 \mathrm{M}$ & $12.4 \mathrm{M}$ \\
\hline Chen & 2015 & GEMOX + & $\mathrm{rP} 2$ & Negative & 62 & $27.4 \%$ & $6.7 \mathrm{M}$ & $10.6 \mathrm{M}$ \\
\hline et al. [25] & & GEMOX & & & 60 & $16.7 \%$ & $4.1 \mathrm{M}$ & $9.8 \mathrm{M}$ \\
\hline Leone & 2016 & GEMOX + & $\mathrm{rP2}$ & Negative & 45 & $24.4 \%$ & $7.7 \mathrm{M}$ & $9.5 \mathrm{M}$ \\
\hline et al. [26] & 2010 & GEMOX & 112 & & 44 & $18.2 \%$ & $5.5 \mathrm{M}$ & $9.9 \mathrm{M}$ \\
\hline Vogel & 2018 & $\begin{array}{c}\text { GemCis + } \\
\text { Pmab }\end{array}$ & rP2 & Negative & 62 & $45.2 \%$ & $6.5 \mathrm{M}$ & $12.8 \mathrm{M}$ \\
\hline et al. [27] & & GemCis & & & 28 & $39.3 \%$ & $8.3 \mathrm{M}$ & $20.1 \mathrm{M}$ \\
\hline Valle & 2015 & $\begin{array}{l}\text { GemCis + } \\
\text { Cediranib }\end{array}$ & rP2 & Negative & 62 & $44.1 \%$ & $7.7 \mathrm{M}$ & $14.1 \mathrm{M}$ \\
\hline et al. [28] & & GemCis & & & 62 & $18.5 \%$ & $7.4 \mathrm{M}$ & $11.9 \mathrm{M}$ \\
\hline Moehler & 2014 & $\underset{\text { GEM + }}{\text { Gorafenib }}$ & $\mathrm{rP} 2$ & Negative & 52 & $14.3 \%$ & $3.0 \mathrm{M}$ & $8.4 \mathrm{M}$ \\
\hline et al. [29] & & GEM & & & 50 & $10.0 \%$ & $4.9 \mathrm{M}$ & $11.2 \mathrm{M}$ \\
\hline
\end{tabular}


Table 1. Cont.

\begin{tabular}{|c|c|c|c|c|c|c|c|c|}
\hline Authors & Year & Regimen & Phase & Result & $\mathbf{N}$ & $\mathbf{R R}$ & Median PFS & Median OS \\
\hline \multirow{3}{*}{$\begin{array}{l}\text { Santoro } \\
\text { et al. [30] }\end{array}$} & \multirow{3}{*}{2015} & $\begin{array}{c}\text { GEM + } \\
\text { Vandetanib }\end{array}$ & \multirow{3}{*}{$\mathrm{rP} 2$} & \multirow{3}{*}{ Negative } & 58 & $19.3 \%$ & $3.8 \mathrm{M}$ & $9.5 \mathrm{M}$ \\
\hline & & GEM & & & 56 & $13.5 \%$ & $4.9 \mathrm{M}$ & $10.2 \mathrm{M}$ \\
\hline & & Vandetanib & & & 59 & $3.6 \%$ & $3.5 \mathrm{M}$ & $7.6 \mathrm{M}$ \\
\hline \multirow{2}{*}{$\begin{array}{l}\text { Schnizari } \\
\text { et al. [31] }\end{array}$} & \multirow{2}{*}{2017} & FOLFOX4 & \multirow{2}{*}{$\mathrm{rP} 2$} & \multirow{2}{*}{ Positive } & 25 & $28.0 \%$ & $5.2 \mathrm{M}$ & $13.0 \mathrm{M}$ \\
\hline & & $5 F U$ + LV & & & 23 & $21.7 \%$ & $2.8 \mathrm{M}$ & $7.5 \mathrm{M}$ \\
\hline \multirow{2}{*}{$\begin{array}{c}\text { Markussen } \\
\text { et al. [32] }\end{array}$} & \multirow[t]{2}{*}{2020} & $\begin{array}{l}\text { GEMOX + } \\
\text { Cape }\end{array}$ & \multirow[t]{2}{*}{$\mathrm{rP} 2$} & \multirow[t]{2}{*}{ Negative } & 47 & $17.0 \%$ & $5.7 \mathrm{M}$ & $8.7 \mathrm{M}$ \\
\hline & & GemCis & & & 49 & $16.3 \%$ & $7.3 \mathrm{M}$ & $12.0 \mathrm{M}$ \\
\hline \multirow{2}{*}{$\begin{array}{c}\text { dos Santos } \\
\text { et al. [33] }\end{array}$} & \multirow{2}{*}{2020} & $\begin{array}{c}\text { CPT-11 + } \\
\text { CDDP }\end{array}$ & \multirow{2}{*}{$\mathrm{rP} 2$} & \multirow{2}{*}{ Positive } & 24 & $35 \%$ & $5.3 \mathrm{M}$ & $11.9 \mathrm{M}$ \\
\hline & & GemCis & & & 23 & $31.8 \%$ & $7.8 \mathrm{M}$ & $9.8 \mathrm{M}$ \\
\hline
\end{tabular}

N; number, RR; response rate, PFS; progression-free survival, OS; overall survival, M; months, rP2; randomized phase II study, GemCis; gemcitabine + cisplatin, GEM; gemcitabine, GEMOX; gemcitabine + oxaliplatin, 5FU; 5-fluorouracil, FA; folinic acid, BSC; best supportive care, CDDP; cisplatin, Cape; capecitabine, mFOLFIRINOX; modified FOLFIRINOX (5-fluorouracil + leucovorin + irinotecan + oxaliplatin), Cmab; cetuximab, Pmab; panitumumab; FOLFOX; 5-fluorouracil + leucovorin + oxaliplatin, LV; leucovorin, CPT-11; irinotecan.

S-1 is an oral fluoropyrimidine derivative used mainly in Asian countries. The combination of gemcitabine and S-1 was widely evaluated in phase II and randomized phase II studies in Japan [34-37]. Based on these results, a randomized phase III study comparing gemcitabine and S-1 combination chemotherapy with gemcitabine and cisplatin combination chemotherapy was conducted in Japan [18]. This study was conducted to evaluate the non-inferiority of gemcitabine and S-1 combination chemotherapy compared to gemcitabine and cisplatin combination chemotherapy. Patients with advanced biliary tract cancer were randomly assigned either gemcitabine and S-1 combination chemotherapy or gemcitabine and cisplatin combination chemotherapy. The primary endpoint was overall survival. The median overall survivals were 15.1 months and 13.4 months, respectively (hazard ratio $0.945, p=0.046$ for non-inferiority). Because the toxicities of gemcitabine and S-1 combination chemotherapy were deemed acceptable, this new doublet also became the standard of care for patients with advanced biliary tract cancer. The major grade $3 / 4$ adverse event of gemcitabine and S- 1 combination chemotherapy was neutropenia. We also need to pay attention to diarrhea, oral mucositis, maculopapular rash, and skin hyperpigmentation. S-1 was also evaluated as the triplet with gemcitabine and cisplatin. Based on the good result of a phase II study evaluating the efficacy of gemcitabine + cisplatin + S-1 combination chemotherapy [38], a phase III study was conducted to confirm the superiority of this triplet over gemcitabine and cisplatin combination chemotherapy in Japan [19]. Two hundred forty-six patients with advanced biliary tract cancer were randomized 1:1 to receive either the triplet or the doublet chemotherapy. The primary endpoint was overall survival. The median overall survivals of gemcitabine + cisplatin + S-1 combination chemotherapy and gemcitabine + cisplatin combination chemotherapy were 13.5 months and 12.6 months, respectively (hazard ratio $0.791, p=0.046$ ). This adverse event's profile of the triplet chemotherapy was also acceptable. The major grade $3 / 4$ adverse event of triplet chemotherapy was also neutropenia. This triplet is also needed to pay attention to diarrhea, stomatitis, and rash. Therefore, gemcitabine + cisplatin + S-1 combination chemotherapy is currently considered a standard regimen for advanced cases.

In summary, the global standard first-line chemotherapy for advanced biliary tract cancer is still gemcitabine and cisplatin combination chemotherapy. In Japan, gemcitabine + S-1 combination chemotherapy and gemcitabine + cisplatin + S-1 combination chemotherapy are also considered alternatives of gemcitabine + cisplatin combination chemotherapy in the first-line setting.

\section{Second-Line Chemotherapy for Advanced Biliary Tract Cancer}

The usefulness of second-line chemotherapy has been reported based on a systematic review and large retrospective studies, but standard treatment has not been 
established [39-45]. In Japan, S-1 is widely used as monotherapy in the clinical setting $[46,47]$. To establish the standard treatment of second-line chemotherapy, various treatments such as molecular-targeted agents and immunotherapy are being developed in addition to conventional cytotoxic agents [48]. Recently, several randomized phase II and phase III studies were reported, some of which showed positive results. Table 2 summarizes previous randomized controlled studies of second-line or third-line chemotherapy for advanced biliary tract cancer.

Table 2. Randomized controlled studies on second-line or third-line chemotherapy for advanced biliary tract cancer.

\begin{tabular}{|c|c|c|c|c|c|c|c|c|}
\hline Authors & Year & Regimen & Phase & Result & $\mathbf{N}$ & RR & Median PFS & Median OS \\
\hline \multirow{2}{*}{$\begin{array}{l}\text { Abou-Alfa } \\
\text { et al. [49] }\end{array}$} & \multirow{2}{*}{2020} & Ivosidenib & \multirow{2}{*}{3} & \multirow{2}{*}{ Positive } & 124 & $2.4 \%$ & $2.7 \mathrm{M}$ & $10.8 \mathrm{M}$ \\
\hline & & BSC & & & 61 & $0 \%$ & $1.4 \mathrm{M}$ & $9.7 \mathrm{M}$ \\
\hline \multirow{2}{*}{$\begin{array}{l}\text { Lamarca } \\
\text { et al. [50] }\end{array}$} & \multirow{2}{*}{2021} & FOLFOX & \multirow{2}{*}{3} & \multirow{2}{*}{ Positive } & 81 & $4.9 \%$ & $4.0 \mathrm{M}$ & $6.2 \mathrm{M}$ \\
\hline & & ASC & & & 81 & - & - & $5.3 \mathrm{M}$ \\
\hline \multirow{2}{*}{$\begin{array}{l}\text { Jalve } \\
\text { et al. [51] }\end{array}$} & \multirow{2}{*}{2020} & $\begin{array}{c}\text { Cape + } \\
\text { Varlitinib }\end{array}$ & \multirow{2}{*}{$2 / 3$} & \multirow{2}{*}{ Negative } & 64 & $9.4 \%$ & $2.8 \mathrm{M}$ & $7.8 \mathrm{M}$ \\
\hline & & Cape & & & 63 & $4.8 \%$ & $2.8 \mathrm{M}$ & $7.5 \mathrm{M}$ \\
\hline \multirow{2}{*}{$\begin{array}{l}\text { Cereda } \\
\text { et al. [52] }\end{array}$} & \multirow{2}{*}{2016} & $\begin{array}{l}\text { Cape + } \\
\text { MMC }\end{array}$ & \multirow{2}{*}{$\mathrm{rP} 2$} & \multirow{2}{*}{ Negative } & 29 & $3.4 \%$ & $2.3 \mathrm{M}$ & $8.1 \mathrm{M}$ \\
\hline & & Cape & & & 28 & $0 \%$ & $2.1 \mathrm{M}$ & $9.5 \mathrm{M}$ \\
\hline \multirow{2}{*}{$\begin{array}{l}\text { Zheng } \\
\text { et al. [53] }\end{array}$} & \multirow{2}{*}{2018} & $\begin{array}{c}\text { Cape + } \\
\text { Irinotecan }\end{array}$ & \multirow{2}{*}{$\mathrm{rP} 2$} & \multirow{2}{*}{ Positive } & 30 & $13.3 \%$ & $3.7 \mathrm{M}$ & $10.1 \mathrm{M}$ \\
\hline & & Irinotecan & & & 30 & $6.7 \%$ & $2.4 \mathrm{M}$ & $7.3 \mathrm{M}$ \\
\hline \multirow{2}{*}{$\begin{array}{l}\text { Kim } \\
\text { et al. [54] }\end{array}$} & \multirow{2}{*}{2020} & Trametinib & \multirow{2}{*}{$\mathrm{rP} 2$} & \multirow{2}{*}{ Negative } & 24 & $8.3 \%$ & $1.4 \mathrm{M}$ & $4.3 \mathrm{M}$ \\
\hline & & $\begin{array}{c}5 \mathrm{FU}+\mathrm{LV} \text { or } \\
\text { Cape }\end{array}$ & & & 20 & $10.0 \%$ & $3.3 \mathrm{M}$ & $6.6 \mathrm{M}$ \\
\hline \multirow{2}{*}{$\begin{array}{l}\text { Demols } \\
\text { et al. [55] }\end{array}$} & \multirow{2}{*}{2020} & Regorafenib & \multirow{2}{*}{$\mathrm{rP} 2$} & \multirow{2}{*}{ Positive } & 33 & $0 \%$ & $3.0 \mathrm{M}$ & $5.3 \mathrm{M}$ \\
\hline & & BSC & & & 33 & $0 \%$ & $1.5 \mathrm{M}$ & $5.1 \mathrm{M}$ \\
\hline \multirow{2}{*}{$\begin{array}{l}\text { Ueno } \\
\text { et al. [56] }\end{array}$} & \multirow{2}{*}{2021} & $\begin{array}{c}\text { S-1 + } \\
\text { Resminostat }\end{array}$ & \multirow[t]{2}{*}{$\mathrm{rP} 2$} & \multirow[t]{2}{*}{ Negative } & 50 & $6.0 \%$ & $2.9 \mathrm{M}$ & $7.8 \mathrm{M}$ \\
\hline & & S-1 & & & 51 & $9.8 \%$ & $3.0 \mathrm{M}$ & $7.5 \mathrm{M}$ \\
\hline \multirow{2}{*}{$\begin{array}{c}\text { Ramaswamy } \\
\text { et al. [57] }\end{array}$} & \multirow{2}{*}{2021} & $\begin{array}{c}\text { Cape + } \\
\text { Irinotecan }\end{array}$ & $\mathrm{rP} 2$ & Negative & 49 & $6.1 \%$ & $2.3 \mathrm{M}$ & $5.2 \mathrm{M}$ \\
\hline & & Irinotecan & & & 49 & $0 \%$ & $3.1 \mathrm{M}$ & $6.3 \mathrm{M}$ \\
\hline Yoo & 2021 & $\begin{array}{c}5 \mathrm{FU}+\mathrm{LV}+ \\
\text { nal-IRI }\end{array}$ & $\mathrm{rP} 2$ & Positive & 88 & $14.8 \%$ & $7.1 \mathrm{M}$ & $8.6 \mathrm{M}$ \\
\hline et al. [58] & & $5 \mathrm{FU}+\mathrm{LV}$ & & & 86 & $5.8 \%$ & $1.4 \mathrm{M}$ & $5.5 \mathrm{M}$ \\
\hline
\end{tabular}

$\mathrm{N}$; number, RR; response rate, PFS; progression-free survival, OS; overall survival, M; months, rP2; randomized phase 2 study, BSC; best supportive care, FOLFOX; 5-fluorouracil + leucovorin + oxaliplatin, ASC; active symptom control, Cape; capecitabine, MMC; mitomycin-C, 5FU; 5-fluorouracil, LV; leucovorin, nal-IRI; nano-liposomal irinotecan.

A phase III study (ABC-06) comparing FOLFOX (5-fluorouracil + leucovorin + oxaliplatin) and active symptom control was conducted in the United Kingdom [50]. Patients with advanced biliary tract cancer treated previously with gemcitabine and cisplatin combination chemotherapy were included. Enrolled patients were randomized to receive either FOLFOX or active symptom control, which was the equivalent of best supportive care. Patients in the active symptom control group could receive FOLFOX after radiographic disease progression was confirmed. The primary endpoint was overall survival. The median overall survivals of FOLFOX and active symptom control groups were 6.2 months and 5.3 months, respectively (hazard ratio $0.69, p=0.031$ ). The benefit of FOLFOX was consistent across subgroups, including those with platinum sensitivity during first-line chemotherapy. The major grade $3 / 4$ adverse events of FOLFOX were neutropenia, fatigue, and catheter-related infection. We also need to pay attention to peripheral neuropathy. This study was the first prospective phase III study that confirmed the benefit of chemotherapy after combination chemotherapy with gemcitabine and cisplatin. Another positive phase III study that showed the efficacy of second-line chemotherapy was the ClarIDHy study. This study was a global phase III study comparing ivosidenib and best supportive care. 
Ivosidenib is a first-in-class, oral, targeted, small-molecule inhibitor of mutant isocitrate dehydrogenase (IDH) 1 protein. IDH1 mutations occur in up to $20 \%$ of cholangiocarcinomas. Patients with advanced cholangiocarcinoma who had received 1-2 prior therapies were enrolled in this study. Patients were randomly assigned to either the ivosidenib group or the best supportive care group. The primary endpoint was progression-free survival. The median progression-free survivals of the ivosidenib and best supportive care groups were 2.7 months and 1.4 months, respectively (hazard ratio $0.37, p<0.001$ ). The major grade $3 / 4$ adverse events of ivosidenib were reported as ascites. This study was the first prospective phase III study that demonstrated a clinical benefit in targeting a molecularly defined subgroup of cholangiocarcinoma and in evaluating genetic profiles of biliary tract cancer. In 2021, the result of a randomized phase II study (NIFTY) comparing 5-fluorouracil + leucovorin + nano-liposomal irinotecan and 5-fluorouracil + leucovorin was reported [58]. This triplet chemotherapy is now known as the NAPOLI regimen and is widely used for second-line chemotherapy in advanced pancreatic cancer. The additional benefit of nano-liposomal irinotecan was demonstrated in this study. Two other randomized phase II studies also showed positive results with capecitabine and irinotecan combination chemotherapy and with regorafenib monotherapy. However, the number of patients enrolled in these studies was relatively small. Therefore, further evaluation is required to establish more solid evidence on these two regimens.

Biliary tract cancers are a heterogeneous group of cancers with different genetic alteration profiles [59-62]. Potential clinically actionable alterations, defined as oncogenic driver alterations with matched therapeutic agents either under investigation or approved in other tumor types, were identified in $44.5 \%$ of patients, showing promise for precision medicine in this field [62]. Common genes implicated in biliary tract cancer tumorigenesis include IDH1, IDH2, fibroblast growth factor receptor (FGFR) 1, FGFR2, FGFR3, and human epidermal growth factor receptor (HER) 2. Encouraging results were seen in patients with identified mutational targets, especially in tumors harboring FGFR2 fusions, HER2, and IDH mutations. The efficacy of an IDH1 inhibitor (ivosidenib) was shown in a phase III study [49]. Several FGFR inhibitors have been evaluated in phase II studies [63-66]. FGFR2 rearrangements were reported in $7.4 \%$ and $3.6 \%$ of Japanese intrahepatic cholangiocarcinoma and perihilar cholangiocarcinoma patients, respectively [67]. Based on the results of a phase II study (FIGHT-202) [65], pemigatinib was approved in many countries for patients with FGFR2 fusion or rearrangement. The major grade $3 / 4$ adverse events of pemigatinib were hypophosphatemia, arthralgia, stomatitis, hyponatremia, abdominal pain, and fatigue.

The efficacies of pembrolizumab for microsatellite instability (MSI)-high solid tumors [68] and neurotrophic tyrosine receptor kinase (NTRK) inhibitors (entrectinib and larotrectinib) for solid tumors with NTRK fusion have also been reported [69,70]. Only a few biliary tract cancer patients were included in these studies, owing to the rarity of these alterations. MSI-high biliary tract cancer was reported in $2.22 \%$ and $1.50 \%$ of Japanese cholangiocarcinoma and gallbladder cancer patients, respectively [71]. NTRK fusion positivity was reported in only $0.18 \%$ of biliary tract cancers [72]. The efficacy and safety of pembrolizumab were evaluated in KEYNOTE-028 and KEYNOTE-158 [73]. Pembrolizumab provides durable antitumor activity in 6-13\% of patients with advanced biliary tract cancer regardless of programmed cell death 1 ligand 1 (PD-L1) expression and has manageable toxicity. Other immune checkpoint inhibitors were also evaluated in phase I or II studies involving both naïve and refractory advanced biliary tract cancer [74-79]. The results of these studies were promising, and further large-scale evaluation is underway. When using these immune checkpoint inhibitors, appropriate management of immune-related adverse events is required.

In summary, FOLFOX is becoming the standard second-line chemotherapy for refractory cases. The presence of IDH mutations, FGFR fusion/rearrangement and NTRK fusion, as well as MSI status, should be confirmed to consider treatment with relevant inhibitors or immune checkpoint inhibitors where applicable. It is also important to consider par- 
ticipation in clinical studies if molecular-targeted agents matched with identified gene alterations are available.

\section{Adjuvant Chemotherapy for Resected Biliary Tract Cancer}

While surgical resection is regarded as the only treatment with a chance of curing biliary tract cancer, postoperative recurrence can sometimes occur. However, standard adjuvant chemotherapy has not been established to date.

Several phase III studies have been reported on adjuvant chemotherapy for resected biliary tract cancer. The first phase III study evaluated the efficacy of adjuvant chemotherapy of 5-fluorouracil + mitomycin- $C$ versus surgery alone in patients with resected pancreaticobiliary carcinoma [80]. Results indicated that gallbladder carcinoma patients who underwent noncurative resection may derive some benefit from systemic chemotherapy. However, alternative modalities must be developed for patients with carcinomas of the pancreas, bile duct, or ampulla of Vater. Several prospective phase III studies focused on adjuvant chemotherapy for biliary tract cancer were subsequently conducted, as summarized in Table 3.

Table 3. Randomized controlled studies of adjuvant chemotherapy for resected biliary tract cancer.

\begin{tabular}{|c|c|c|c|c|c|c|c|c|}
\hline Authors & Year & Biliary Site & Regimen & Phase & Result & $\mathbf{N}$ & Median RFS & Median OS \\
\hline $\begin{array}{l}\text { Neoptolemos } \\
\text { et al. [81] }\end{array}$ & 2012 & $\mathrm{EHCC}, \mathrm{AC}$ & $\begin{array}{c}\text { 5FU + FA } \\
\text { GEM } \\
\text { Surgery alone }\end{array}$ & 3 & Marginal & $\begin{array}{l}143 \\
141 \\
144\end{array}$ & $\begin{array}{l}23.0 \mathrm{M} \\
29.1 \mathrm{M} \\
19.5 \mathrm{M}\end{array}$ & $\begin{array}{l}38.9 \mathrm{M} \\
45.7 \mathrm{M} \\
35.2 \mathrm{M}\end{array}$ \\
\hline $\begin{array}{c}\text { Ebata } \\
\text { et al. [82] }\end{array}$ & 2018 & EHCC & $\begin{array}{c}\text { GEM } \\
\text { Surgery alone }\end{array}$ & 3 & Negative & $\begin{array}{l}117 \\
108\end{array}$ & $\begin{array}{l}36.0 \mathrm{M} \\
39.9 \mathrm{M}\end{array}$ & $\begin{array}{l}62.3 \mathrm{M} \\
63.8 \mathrm{M}\end{array}$ \\
\hline $\begin{array}{l}\text { Edeline } \\
\text { et al. [83] }\end{array}$ & 2019 & $\begin{array}{c}\text { ICC, EHCC, } \\
\text { GBC }\end{array}$ & $\begin{array}{c}\text { GEMOX } \\
\text { Surgery alone }\end{array}$ & 3 & Negative & $\begin{array}{l}94 \\
99\end{array}$ & $\begin{array}{l}30.4 \mathrm{M} \\
18.5 \mathrm{M}\end{array}$ & $\begin{array}{l}75.8 \mathrm{M} \\
50.8 \mathrm{M}\end{array}$ \\
\hline $\begin{array}{l}\text { Primrose } \\
\text { et al. [84] }\end{array}$ & 2019 & $\begin{array}{c}\text { ICC, EHCC, } \\
\text { GBC }\end{array}$ & $\begin{array}{l}\text { Capecitabine } \\
\text { Surgery alone }\end{array}$ & 3 & Marginal & $\begin{array}{l}223 \\
224\end{array}$ & $\begin{array}{l}24.4 \mathrm{M} \\
17.5 \mathrm{M}\end{array}$ & $\begin{array}{l}51.1 \mathrm{M} \\
36.4 \mathrm{M}\end{array}$ \\
\hline
\end{tabular}

N; number, RFS; recurrent-free survival, OS; overall survival, M; months, EHCC; extrahepatic cholangiocarcinoma, AC; ampullary cancer, ICC; intrahepatic cholangiocarcinoma, GBC; gallbladder cancer, 5FU; 5-fluorouracil, FA; folinic acid, GEM; gemcitabine, GEMOX; gemcitabine + oxaliplatin.

ESPAC-3 was a phase III study that evaluated the efficacy of adjuvant chemotherapy using 5-fluorouracil + folinic acid or gemcitabine monotherapy against surgery alone [81]. Patients with extrahepatic cholangiocarcinoma and ampullary cancer were enrolled in this study. This study did not show superiority of adjuvant chemotherapy over surgery alone based on an intention-to-treat analysis. However, sensitivity analysis adjusted for prognostic factors showed improved prognosis in both the adjuvant chemotherapy group and the gemcitabine monotherapy group compared to the surgery alone group. BCAT was a phase III study conducted to evaluate the efficacy of adjuvant chemotherapy using gemcitabine against surgery alone [82]. This Japanese study was limited to extrahepatic cholangiocarcinoma patients. Treatment outcomes of surgery alone were extremely good, and no additional benefits of gemcitabine were observed. PRODIGE 12-ACCORD 18 was a French phase III study that compared adjuvant gemcitabine and oxaliplatin combination chemotherapy with surgery alone [83]. All types of biliary tract cancer other than ampullary cancer were included. The efficacy of adjuvant combination chemotherapy was not demonstrated in this negative study. BILCAP was a British phase III study that compared adjuvant capecitabine and surgery alone [84]. While capecitabine monotherapy failed to show improvement based on an intention-to-treat analysis, significant improvement was demonstrated in a per-protocol analysis. The major grade $3 / 4$ adverse events of capecitabine were hand-foot syndrome, diarrhea and fatigue. Because of this promising result, the American Society of Clinical Oncology guideline recommends adjuvant capecitabine monotherapy for resected biliary tract cancer [85]. 
In summary, capecitabine monotherapy of six months for adjuvant chemotherapy is considered standard treatment for resected biliary tract cancer in Western counties. Until prospective studies show otherwise, surgery alone remains the standard of care in Japan.

\section{Ongoing Clinical Trials for Biliary Tract Cancer}

Currently, effective chemotherapy for biliary tract cancer is extremely limited, and the development of new therapies is urgently needed. There are a large number of ongoing prospective studies for biliary tract cancer [86-91]. Based on promising early-phase study results, phase III studies are underway [92-94]. A list of major ongoing randomized controlled studies for biliary tract cancer is provided in Table 4 . In addition to conventional treatments using cytotoxic agents, a wide variety of drugs such as molecular-targeted agents and immune checkpoint inhibitors are being investigated. Despite the low frequency of genetic alterations, precision medicine with molecular-targeted agents holds promise for selected patients. Umbrella and basket studies are increasingly being conducted, based on the need to build a mechanism to provide drugs suited to each genetic alteration regardless of tumor origin. The efficacy of immunotherapy combined with conventional treatment is also being investigated. In addition, a new large-scale trial for neoadjuvant chemotherapy is underway. Many new therapies that enhance the effectiveness of current regimens have been validated in late-phase clinical trials such as those listed in Table 4. On the other hand, many new drugs have been validated in other, slightly earlier phase clinical trials. It is hoped that such drugs will advance to late-phase clinical trials sooner. Like other cancers, it is also expected that molecular-targeted drugs and immunotherapy that matched cancer genetic characteristics, such as first-line FGFR inhibitors, can produce much better treatment than current standard treatments.

Table 4. Major ongoing clinical studies for biliary tract cancer.

\begin{tabular}{|c|c|c|c|}
\hline Regimen & $\mathbf{N}$ & Phase & Trial ID \\
\hline \multicolumn{4}{|l|}{ First-line chemotherapy } \\
\hline NUC-1031 (Acelarin) + CDDP vs. GemCis (NuTide:121) & 828 & 3 & NCT04163900 \\
\hline GemCis + Pembrolizumab vs. GemCis (KEYNOTE-966) & 788 & 3 & NCT04003636 \\
\hline GemCis + Durvalumab vs. GemCis (TOPAZ-1) & 757 & 3 & NCT03875235 \\
\hline Pemigatinib vs. GemCis (FIGHT-302) & 432 & 3 & NCT03656536 \\
\hline GEMOX + KN035 vs. GEMOX (KN035-BTC) & 390 & 3 & NCT03478488 \\
\hline Infigratinib vs. GemCis (PROOF 301 trial) & 384 & 3 & NCT037773302 \\
\hline GemCis + nab-paclitaxel vs. GemCis (SWOG/S1815) & 268 & 3 & NCT03768414 \\
\hline Futibatinib vs. GemCis (FOENIX-CCA3) & 216 & 3 & NCT04093362 \\
\hline GemCis + Bintrafusp alfa vs. GemCis & 512 & $2 / 3$ & NCT04066491 \\
\hline \multicolumn{4}{|l|}{ Second-line chemotherapy } \\
\hline TQB2450 + Anlotinib vs. Cape + Oxaliplatin or Cape + GEM & 392 & 3 & NCT04809142 \\
\hline Surufatinib vs. Cape & 298 & $2 / 3$ & NCT03873532 \\
\hline \multicolumn{4}{|l|}{ Adjuvant chemotherapy } \\
\hline GemCis vs. Surgery alone or Cape (ACTICCA-1) & 781 & 3 & NCT02170090 \\
\hline GEM + Cape vs. Cape (AdBTC-1) & 460 & 3 & NCT03779035 \\
\hline S-1 vs. Surgery alone (ASCOT) & 350 & 3 & UMIN000011688 \\
\hline \multicolumn{4}{|l|}{ Neoadjuvant chemotherapy } \\
\hline Neoadjuvant \& adjuvant GemCis vs. Adjuvant CTx (GAIN) & 300 & 3 & NCT03673072 \\
\hline Neoadjuvant GCS vs. Surgery first (NABICAT) & 300 & 3 & jRCTs031200388 \\
\hline
\end{tabular}

CDDP; cisplatin, GemCis; gemcitabine + cisplatin, GEMOX; gemcitabine + oxaliplatin, Cape; capecitabine, GEM; gemcitabine, CTx; chemotherapy, GCS; gemcitabine + cisplatin + S-1.

\section{Conclusions}

Figure 1 shows the proposed treatment algorithm of chemotherapy for advanced biliary tract cancer in 2021. It is necessary to arrange this algorithm according to the medical situation in each country. 


\section{First-line chemotherapy}

Second-line chemotherapy

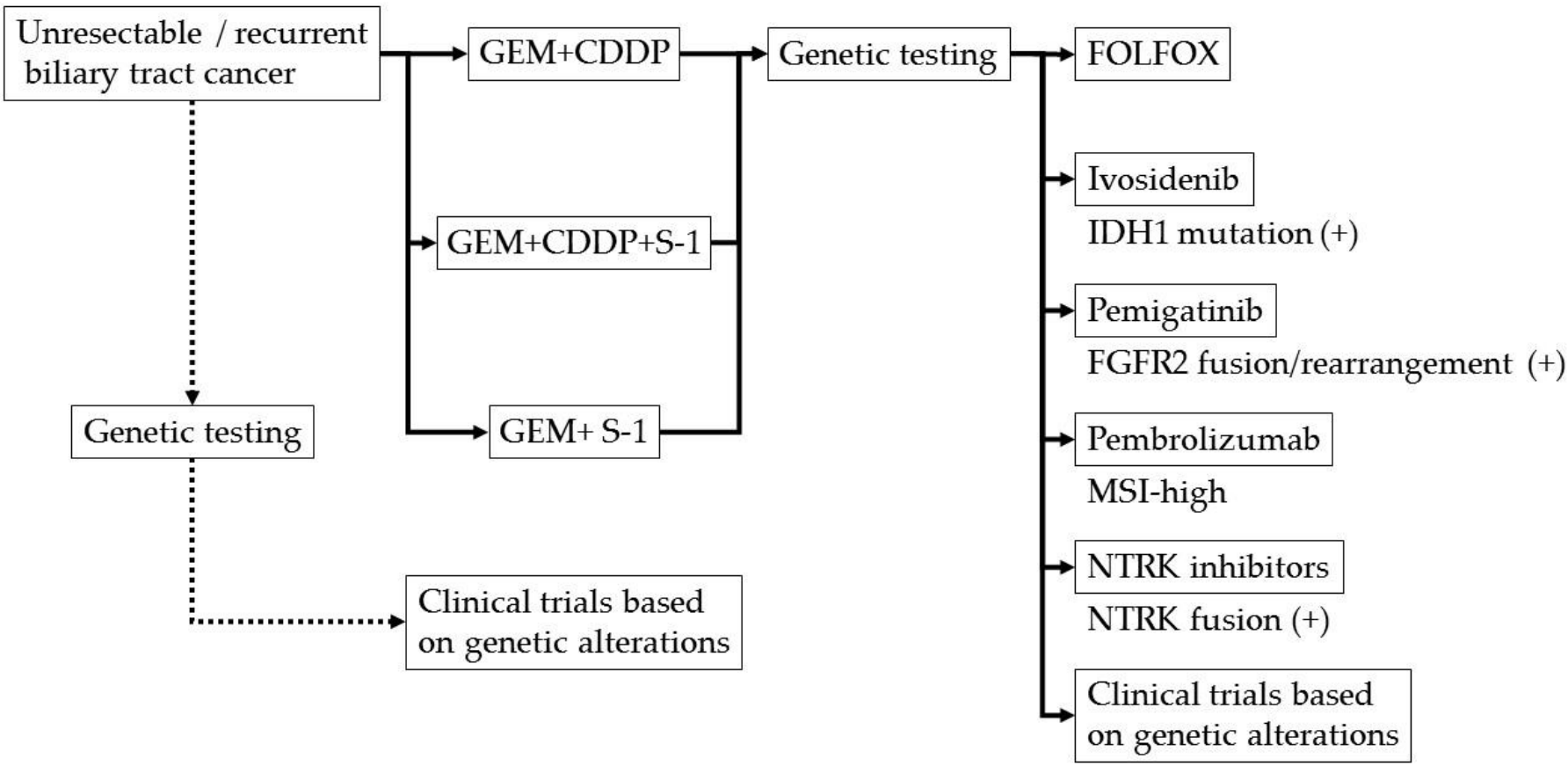

Figure 1. Proposed treatment algorithm of chemotherapy for advanced biliary tract cancer. GEM; gemcitabine, CDDP; cisplatin, FOLFOX; 5-fluorouracil + leucovorin + oxaliplatin, IDH; isocitrate dehydrogenase, FGFR; fibroblast growth factor receptor, MSI; microsatellite instability, NTRK; neurotrophic tyrosine receptor kinase.

Biliary tract cancer is considered a population with various genetic alterations. Genetic alterations are often measured before starting second- or third-line chemotherapy only in patients who are able to get enough tissue samples. If the effectiveness of moleculartargeted drugs and immunotherapy based on the characteristics of cancer is shown at first-line setting, it is thought that the trend of investigating genetic alterations from the time of diagnosis will accelerate in the future. In addition, to overcome the problem that biliary tract cancer is sometimes difficult to get enough tissue samples, there are great expectations for liquid biopsy in this field. Furthermore, there is an urgent need to develop more drugs that match genetic alterations and establish a system to deliver the drugs to the matched patients in clinical practice.

While evidence relating to chemotherapy for biliary tract cancer had been limited, numerous clinical studies have been conducted in the last decade and evidence is steadily accumulating. Many large-scale clinical studies are still underway, some of which may lead to improved treatment outcomes going forward.

Author Contributions: Writing—original draft preparation, T.S.; writing—review and editing, T.T., T.O., supervision, M.O., N.S. All authors have read and agreed to the published version of the manuscript.

Funding: This research received no external funding.

Informed Consent Statement: Not applicable.

Data Availability Statement: Not applicable.

Conflicts of Interest: T.S. has received honoraria from Taiho Pharmaceutical Co., Ltd., Yakult Honsha Co., Ltd., Eisai Co., Ltd. T.T. has received honoraria from Taiho Pharmaceutical Co., Ltd. M.O. has received honoraria from Taiho Pharmaceutical Co., Ltd., Yakult Honsha Co., Ltd., Eisai Co., Ltd., AstraZeneca, ONO Pharmaceutical Co., Ltd., Chugai Pharmaceutical Co., Novartis, MSD. N.S. has received research grants from Taiho Pharmaceutical Co., Ltd., Chugai Pharmaceutical Co., Ltd., and 
has received honoraria Chugai Pharmaceutical Co., Ltd., Eisai Co., Ltd. The other author declares no conflicts of interest.

\section{References}

1. Valle, J.W.; Kelley, R.K.; Nervi, B.; Oh, D.Y.; Zhu, A.X. Biliary tract cancer. Lancet 2021, 397, 428-444. [CrossRef]

2. Siegel, R.L.; Miller, K.D.; Fuchs, H.E.; Jemal, A. Cancer Statistics, 2021. CA. Cancer J. Clin. 2021, 71, 7-33. [CrossRef] [PubMed]

3. Sung, H.; Ferlay, J.; Siegel, R.L.; Laversanne, M.; Soerjomataram, I.; Jemal, A.; Bray, F. Global Cancer Statistics 2020: GLOBOCAN Estimates of Incidence and Mortality Worldwide for 36 Cancers in 185 Countries. CA. Cancer J. Clin. 2021, 71, 209-249. [CrossRef]

4. Florio, A.A.; Ferlay, J.; Znaor, A.; Ruggieri, D.; Alvarez, C.S.; Laversanne, M.; Bray, F.; McGlynn, K.A.; Petrick, J.L. Global trends in intrahepatic and extrahepatic cholangiocarcinoma incidence from 1993 to 2012. Cancer 2020, 126, 2666-2678. [CrossRef] [PubMed]

5. Gad, M.M.; Saad, A.M.; Faisaluddin, M.; Gaman, M.A.; Ruhban, I.A.; Jazieh, K.A.; Al-Husseini, M.J.; Simons-Linares, C.R. Epidemiology of Cholangiocarcinoma; United States Incidence and Mortality Trends. Clin. Res. Hepatol. Gastroenterol. 2020, 44, 885-893. [CrossRef] [PubMed]

6. Rawla, P.; Sunkara, T.; Thandra, K.C.; Barsouk, A. Epidemiology of gallbladder cancer. Clin. Exp. Hepatol. 2019, 5, 93-102. [CrossRef] [PubMed]

7. Cancer Registry and Statistics. Cancer Information Service, National Cancer Center, Japan (Vital Statistics of Japan). Available online: https://ganjoho.jp/reg_stat/statistics/dl/index.html (accessed on 1 June 2021).

8. Ishihara, S.; Horiguchi, A.; Miyakawa, S.; Endo, I.; Miyazaki, M.; Takada, T. Biliary tract cancer registry in Japan from 2008 to 2013. J. Hepatobiliary Pancreat. Sci. 2016, 23, 149-157. [CrossRef] [PubMed]

9. Glimelius, B.; Hoffman, K.; Sjödén, P.O.; Jacobsson, G.; Sellström, H.; Enander, L.K.; Linné, T.; Svensson, C. Chemotherapy improves survival and quality of life in advanced pancreatic and biliary cancer. Ann. Oncol. 1996, 7, 593-600. [CrossRef]

10. Sharma, A.; Dwary, A.D.; Mohanti, B.K.; Deo, S.V.; Pal, S.; Sreenivas, V.; Raina, V.; Shukla, N.K.; Thulkar, S.; Garg, P.; et al. Best supportive care compared with chemotherapy for unresectable gall bladder cancer: A randomized controlled study. J. Clin. Oncol. 2010, 28, 4581-4586. [CrossRef]

11. Eckel, F.; Schmid, R.M. Chemotherapy in advanced biliary tract carcinoma: A pooled analysis of clinical trials. Br. J. Cancer 2007, 96, 896-902. [CrossRef]

12. Valle, J.W.; Wasan, H.; Johnson, P.; Jones, E.; Dixon, L.; Swindell, R.; Baka, S.; Maraveyas, A.; Corrie, P.; Falk, S.; et al. Gemcitabine alone or in combination with cisplatin in patients with advanced or metastatic cholangiocarcinomas or other biliary tract tumours: A mulitcentre randomized phase II study-The UK ABC-01 Study. Br. J. Cancer 2009, 101, 621-627. [CrossRef]

13. Valle, J.; Wasan, H.; Palmer, D.H.; Cunningham, D.; Anthoney, A.; Maraveyas, A.; Madhusudan, S.; Iveson, T.; Hughes, S.; Pereira, S.P.; et al. Cisplatin plus gemcitabine versus gemcitabine for biliary tract cancer. N. Engl. J. Med. 2010, 362, 1273-1281. [CrossRef] [PubMed]

14. Okusaka, T.; Nakachi, K.; Fukutomi, A.; Mizuno, N.; Ohkawa, S.; Funakoshi, M.; Nagino, M.; Kondo, S.; Nagaoka, S.; Funai, J.; et al. Gemcitabine alone or in combination with cisplatin in patients with biliary tract cancer: A comparative multicentre study in Japan. Br. J. Cancer 2010, 103, 469-474. [CrossRef]

15. Valle, J.W.; Furuse, J.; Jitlal, M.; Beare, S.; Mizuno, N.; Wasan, H.; Bridgewater, J.; Okusaka, T. Cisplatin and gemcitabine for advanced biliary tract cancer: A meta-analysis of two randomized trials. Ann. Oncol. 2014, 25, 391-398. [CrossRef] [PubMed]

16. Sharma, A.; Kalyan Mohanti, B.; Pal Chaudhary, S.; Sreenivas, V.; Kumar Sahoo, R.; Kumar Shukla, N.; Thulkar, S.; Pal, S.; Deo, S.V.; Pathy, S.; et al. Modified gemcitabine and oxaliplatin or gemcitabine + cisplatin in uresectable gallbladder cancer: Results of a phase III randomized controlled trial. Eur. J. Cancer 2019, 123, 162-170. [CrossRef]

17. Lee, J.; Park, S.H.; Chang, H.M.; Kim, J.S.; Choi, H.J.; Lee, M.A.; Jang, J.S.; Jeung, H.C.; Kang, J.H.; Lee, H.W.; et al. Gemcitabine and oxaliplatin with or without erlotinib in advanced biliary-tract cancer: A multicentre, open-label, randomized, phase 3 study. Lancet Oncol. 2012, 13, 181-188. [CrossRef]

18. Morizane, C.; Okusaka, T.; Mizusawa, J.; Katayama, H.; Ueno, M.; Ikeda, M.; Ozaka, M.; Okano, N.; Sugimori, K.; Fukutomi, A.; et al. Combination gemcitabine plus S-1 versus gemcitabine plus cisplatin for advanced/recurrent biliary tract cancer: The FUGA-BT (JCOG1113) randomized phase III clinical trial. Ann. Oncol. 2019, 30, 1950-1958. [CrossRef] [PubMed]

19. Sakai, D.; Kanai, M.; Kobayashi, S.; Eguchi, H.; Baba, H.; Seo, S.; Taketomi, A.; Takayama, T.; Yamaue, H.; Ishioka, C.; et al. Randomized phase III study of gemcitabine, cisplatin plus S-1 (GCS) versus gemcitabine, cisplatin (GC) for advanced biliary tract cancer (KHBO1401-MITSUBA). Ann. Oncol. 2018, 29 (Suppl. 8), viii205-viii270. [CrossRef]

20. Kim, S.T.; Kang, J.H.; Lee, J.; Lee, H.W.; Oh, S.Y.; Jang, J.S.; Lee, M.A.; Sohn, B.S.; Yoon, S.Y.; Choi, H.J.; et al. Capecitabine plus oxaliplatin versus gemcitabine plus oxaliplatin as first-line therapy for advanced biliary tract cancers: A multicenter, open-label, randomized, phase III, noninferiority trial. Ann. Oncol. 2019, 30, 788-795. [CrossRef]

21. Phelip, J.M.; Desrame, J.; Edeline, J.; Barbier, E.; Terrebonne, E.; Michel, P.; Perrier, H.; Dahan, L.; Bourgeois, V.; Khemissa Akouz, F.; et al. Modified FOLFIRINOX versus CISGEM first-line chemotherapy for locally advanced, non resectable and/or metastatic biliary tract cancer: Results of AMEBICA PRODIGE 38 Phase II trial. Ann. Oncol. 2020, 31 (Suppl. 4), S260-S273. [CrossRef]

22. Kang, M.J.; Lee, J.; Kim, T.W.; Lee, S.S.; Ahn, S.; Park, D.H.; Lee, S.S.; Seo, D.W.; Lee, S.K.; Kim, M. Randomized phase II trial of S-1 and cisplatin versus gemcitabine and cisplatin in patients with advanced biliary tract cancer. Acta Oncol. 2012, 7, 860-866. [CrossRef] 
23. Lee, J.; Hong, T.H.; Lee, I.S.; You, Y.K.; Lee, M.A. Comparison of the Efficacy between Gemcitabine-Cisplatin and CapecitabineCisplatin Combination Chemotherapy for Advanced Biliary Tract Cancer. Cancer Res. Treat. 2015, 47, 259-265. [CrossRef]

24. Malka, D.; Cervera, P.; Foulon, S.; Trarbach, T.; de la Fouchardière, C.; Boucher, E.; Fartoux, L.; Faivre, S.; Blanc, J.F.; Viret, F.; et al. Gemcitabine and oxaliplatin with or without cetuximab in advanced biliary-tract cancer (BINGO): A randomised, open-label, non-comparative phase 2 trial. Lancet Oncol. 2014, 15, 819-828. [CrossRef]

25. Chen, J.S.; Hsu, C.; Chiang, N.J.; Tsai, C.S.; Tsou, H.H.; Huang, S.F.; Bai, L.Y.; Chang, I.C.; Shiah, H.S.; Ho, C.L.; et al. A KRAS mutation status-stratified randomized phase II trial of gemcitabine and oxaliplatin alone or in combination with cetuximab in advanced biliary tract cancer. Ann. Oncol. 2015, 26, 943-949. [CrossRef]

26. Leone, F.; Marino, D.; Cereda, S.; Filippi, R.; Belli, C.; Spadi, R.; Nasti, G.; Montano, M.; Amatu, A.; Aprile, G.; et al. Panitumumab in combination with gemcitabine and oxaliplatin does not prolong survival in wild-type KRAS advanced biliary tract cancer: A randomized phase 2 trial (Vecti-BIL study). Cancer 2016, 122, 574-581. [CrossRef] [PubMed]

27. Vogel, A.; Kasper, S.; Bitzer, M.; Block, A.; Sinn, M.; Schulze-Bergkamen, H.; Moehler, M.; Pfarr, N.; Endris, V.; Goeppert, B.; et al. PICCA study: Panitumumab in combination with cisplatin/gemcitabine chemotherapy in KRAS wild-type patients with biliary cancer-a randomised biomarker-driven clinical phase II AIO study. Eur. J. Cancer 2018, 92, 11-19. [CrossRef]

28. Valle, J.W.; Wasan, H.; Lopes, A.; Backen, A.C.; Palmer, D.H.; Morris, K.; Duggan, M.; Cunningham, D.; Anthoney, D.A.; Corrie, P.; et al. Cediranib or placebo in combination with cisplatin and gemcitabine chemotherapy for patients with advanced biliary tract cancer (ABC-03): A randomised phase 2 trial. Lancet Oncol. 2015, 16, 967-978. [CrossRef]

29. Moehler, M.; Maderer, A.; Schimanski, C.; Kanzler, S.; Denzer, U.; Kolligs, F.T.; Ebert, M.P.; Distelrath, A.; Geissler, M.; Trojan, J.; et al. Gemcitabine plus sorafenib versus gemcitabine alone in advanced biliary tract cancer: A double-blind placebo-controlled multicentre phase II AIO study with biomarker and serum programme. Eur. J. Cancer 2014, 50, 3125-3135. [CrossRef]

30. Santoro, A.; Gebbia, V.; Pressiani, T.; Testa, A.; Personeni, N.; Arrivas Bajardi, E.; Foa, P.; Buonadonna, A.; Bencardino, K.; Barone, C.; et al. A randomized, multicenter, phase II study of vandetanib monotherapy versus vandetanib in combination with gemcitabine versus gemcitabine plus placebo in subjects with advanced biliary tract cancer: The VanGogh study. Ann. Oncol. 2015, 26, 542-547. [CrossRef] [PubMed]

31. Schinzari, G.; Rossi, E.; Mambella, G.; Strippoli, A.; Cangiano, R.; Mutignani, M.; Basso, M.; Cassano, A.; Barone, C. First-line Treatment of Advanced Biliary Ducts Carcinoma: A Randomized Phase II Study Evaluating 5-FU/LV Plus Oxaliplatin (Folfox 4) Versus 5-FU/LV (de Gramont Regimen). Anticancer Res. 2017, 37, 5193-5197. [PubMed]

32. Markussen, A.; Jensen, L.H.; Diness, L.V.; Larsen, F.O. Treatment of Patients with Advanced Biliary Tract Cancer with Either Oxaliplatin, Gemcitabine, and Capecitabine or Cisplatin and Gemcitabine-A Randomized Phase II Trial. Cancers 2020, $12,1975$. [CrossRef]

33. dos Santos, L.V.; Pinto, G.S.F.; Ferraz, M.W.S.; Bragagnoli, A.; Santos, F.; Haddad, S.; Barros, A.; Dias, I.C.C.; Lima, J.P.S.; Abdalla, K.C. Cisplatin plus irinotecan versus cisplatin plus gemcitabine in the treatment of advanced or metastatic gallbladder or biliary tract cancer: Results of a randomized phase II trial (NCT01859728)-The Gambit trial. J. Clin. Oncol. 2020, 38 (Suppl. 4), 529. [CrossRef]

34. Sasaki, T.; Isayama, H.; Nakai, Y.; Ito, Y.; Kogure, H.; Togawa, O.; Toda, N.; Yasuda, I.; Hasebe, O.; Maetani, I.; et al. Multicenter, phase II study of gemcitabine and S-1 combination chemotherapy in patients with advanced biliary tract cancer. Cancer Chemother. Pharmacol. 2010, 65, 1101-1107. [CrossRef]

35. Kanai, M.; Yoshimura, K.; Tsumura, T.; Asada, M.; Suzuki, C.; Niimi, M.; Matsumoto, S.; Nishimura, T.; Nitta, T.; Yasuchika, K.; et al. A multi-institution phase II study of gemcitabine/S-1 combination chemotherapy for patients with advanced biliary tract cancer. Cancer Chemother. Pharmacol. 2011, 67, 1429-1434. [CrossRef]

36. Sasaki, T.; Isayama, H.; Nakai, Y.; Ito, Y.; Yasuda, I.; Toda, N.; Kogure, H.; Hanada, K.; Maguchi, H.; Sasahira, N.; et al. A randomized phase II study of gemcitabine and S-1 combination therapy versus gemcitabine monotherapy for advanced biliary tract cancer. Cancer Chemother. Pharmacol. 2013, 71, 973-979. [CrossRef] [PubMed]

37. Morizane, C.; Okusaka, T.; Mizusawa, J.; Takashima, A.; Ueno, M.; Ikeda, M.; Hamamoto, Y.; Ishii, H.; Boku, N.; Furuse, J. Randomized phase II study of gemcitabine plus S-1 versus S-1 in advanced biliary tract cancer: A Japan Clinical Oncology Group trial (JCOG 0805). Cancer Sci. 2013, 104, 1211-1216. [CrossRef] [PubMed]

38. Kanai, M.; Hatano, E.; Kobayashi, S.; Fujiwara, Y.; Marubashi, S.; Miyamoto, A.; Shiomi, H.; Kubo, S.; Ikuta, S.; Yanagimoto, H.; et al. A multi-institution phase II study of gemcitabine/cisplatin/S-1 (GCS) combination chemotherapy for patients with advanced biliary tract cancer (KHBO 1002). Cancer Chemother. Pharmacol. 2015, 75, 293-300. [CrossRef] [PubMed]

39. Walter, T.; Horgan, A.M.; McNamara, M.; McKeever, L.; Min, T.; Hedley, D.; Serra, S.; Krzyzanowska, M.K.; Chen, E.; Mackay, H.; et al. Feasibility and benefits of second-line chemotherapy in advanced biliary tract cancer: A large retrospective study. Eur. J. Cancer 2013, 49, 329-335. [CrossRef]

40. Bridgewater, J.; Palmer, D.; Cunningham, D.; Iveson, T.; Gillmore, R.; Waters, J.; Harrison, M.; Wasan, H.; Corrie, P.; Valle, J. Outcome of second-line chemotherapy for biliary tract cancer. Eur. J. Cancer 2013, 49, 1511. [CrossRef]

41. Lamarca, A.; Hubner, R.A.; David Ryder, W.; Valle, J.W. Second-line chemotherapy in advanced biliary cancer: A systematic review. Ann. Oncol. 2014, 25, 2328-2338. [CrossRef]

42. Brieau, B.; Dahan, L.; De Rycke, Y.; Boussaha, T.; Vasseur, P.; Tougeron, D.; Lecomte, T.; Coriat, R.; Bachet, J.B.; Claudez, P.; et al. Second-line chemotherapy for advanced biliary tract cancer after failure of the gemcitabine-platinum combination: A large multicenter study by the Association des Gastro-Entérologues Oncologues. Cancer 2015, 121, 3290-3297. [CrossRef] 
43. Takahara, N.; Nakai, Y.; Isayama, H.; Sasaki, T.; Saito, K.; Oyama, H.; Kanai, S.; Suzuki, T.; Sato, T.; Hakuta, R.; et al. Second-line chemotherapy in patients with advanced or recurrent biliary tract cancer: A single center, retrospective analysis of 294 cases. Investig. New Drugs 2018, 36, 1093-1102. [CrossRef] [PubMed]

44. Lowery, M.A.; Goff, L.W.; Keenan, B.P.; Jordan, E.; Wang, R.; Bocobo, A.G.; Chou, J.F.; O’Reilly, E.M.; Harding, J.J.; Kemeny, N.; et al. Second-line chemotherapy in advanced biliary cancers: A retrospective, multicenter analysis of outcomes. Cancer 2019, 125, 4426-4434. [CrossRef] [PubMed]

45. Zaidi, A.; Chandna, N.; Narasimhan, G.; Moser, M.; Haider, K.; Chalchal, H.; Shaw, J.; Ahmed, S. Second-line Chemotherapy Prolongs Survival in Real World Patients with Advanced Biliary Tract and Gallbladder Cancers: A Multicenter Retrospective Population-based Cohort Study. Am. J. Clin. Oncol. 2021, 44, 93-98. [CrossRef] [PubMed]

46. Sasaki, T.; Isayama, H.; Nakai, Y.; Mizuno, S.; Yamamoto, K.; Yagioka, H.; Yashima, Y.; Kawakubo, K.; Kogure, H.; Togawa, O.; et al. Multicenter phase II study of S-1 monotherapy as second-line chemotherapy for advanced biliary tract cancer refractory to gemcitabine. Investig. New Drugs 2012, 30, 708-713. [CrossRef]

47. Suzuki, E.; Ikeda, M.; Okusaka, T.; Nakamori, S.; Ohkawa, S.; Nagakawa, Y.; Boku, N.; Yanagimoto, H.; Sato, T.; Furuse, J. A multicenter phase II study of S-1 for gemcitabine-refractory biliary tract cancer. Cancer Chemother. Pharmacol. 2013, 71, 1141-1146. [CrossRef]

48. Tella, S.H.; Kommalapati, A.; Borad, M.J.; Mahipal, A. Second-line therapies in advanced biliary tract cancers. Lancet Oncol. 2020, 21, e29-e41. [CrossRef]

49. Abou-Alfa, G.K.; Macarulla, T.; Javle, M.M.; Kelley, R.K.; Lubner, S.J.; Adeva, J.; Cleary, J.M.; Catenacci, D.V.; Borad, M.J.; Bridgewater, J.; et al. Ivosidenib in IDH1-mutant, chemotherapy-refractory cholangiocarcinoma (ClarIDHy): A multicentre, randomised, double-blind, placebo-controlled, phase 3 study. Lancet Oncol. 2020, 21, 796-807. [CrossRef]

50. Lamarca, A.; Palmer, D.H.; Wasan, H.S.; Ross, P.J.; Ma, Y.T.; Arora, A.; Falk, S.; Gillmore, R.; Wadsley, J.; Patel, K.; et al. Second-line FOLFOX chemotherapy versus active symptom control for advanced biliary tract cancer (ABC-06): A phase 3, open-label, randomised, controlled trial. Lancet Oncol. 2021, 22, 690-701. [CrossRef]

51. Jalve, M.M.; Oh, D.Y.; Ikeda, M.; Yong, W.P.; McIntyre, N.; Lindmark, B.; McHale, M. Results from TreeTopp: A randomized phase II study of the efficacy and safety of varlitinib plus capecitabine versus placebo in second-line (2L) advanced or metastatic biliary tract cancer (BTC). J. Clin. Oncol. 2020, 38 (Suppl. 15), 4597.

52. Cereda, S.; Milella, M.; Cordio, S.; Leone, F.; Aprile, G.; Galiano, A.; Mosconi, S.; Vasile, E.; Santini, D.; Belli, C.; et al. Capecitabine with/without mitomycin C: Results of a randomized phase II trial of second-line therapy in advanced biliary tract adenocarcinoma. Cancer Chemother. Pharmacol. 2016, 77, 109-114. [CrossRef] [PubMed]

53. Zheng, Y.; Tu, X.; Zhao, P.; Jiang, W.; Liu, L.; Tong, Z.; Zhang, H.; Yan, C.; Fang, W.; Wang, W. A randomised phase II study of second-line XELIRI regimen versus irinotecan monotherapy in advanced biliary tract cancer patients progressed on gemcitabine and cisplatin. Br. J. Cancer 2018, 119, 291-295. [CrossRef] [PubMed]

54. Kim, R.D.; McDonough, S.; El-Khoueiry, A.B.; Bekaii-Saab, T.S.; Stein, S.M.; Sahai, V.; Keogh, G.P.; Kim, E.J.; Baron, A.D.; Siegel, A.B.; et al. Randomised phase II trial (SWOG S1310) of single agent MEK inhibitor trametinib Versus 5-fluorouracil or capecitabine in refractory advanced biliary cancer. Eur. J. Cancer 2020, 130, 219-227. [CrossRef] [PubMed]

55. Demols, A.; Borbath, I.; Van den Eynde, M.; Houbiers, G.; Peeters, M.; Marechal, R.; Delaunoit, T.; Goemine, J.C.; Laurent, S.; Holbrechts, S.; et al. Regorafenib after failure of gemcitabine and platinum-based chemotherapy for locally advanced/metastatic biliary tumors: REACHIN, a randomized, double-blind, phase II trial. Ann. Oncol. 2020, 31, 1169-1177. [CrossRef] [PubMed]

56. Ramaswamy, A.; Ostwal, V.; Sharma, A.; Bhargava, P.; Srinivas, S.; Goel, M.; Patkar, S.; Mandavkar, S.; Jadhav, P.; Parulekar, M.; et al. Efficacy of Capecitabine Plus Irinotecan vs Irinotecan Monotherapy as Second-line Treatment in Patients With Advanced Gallbladder Cancer: A Multicenter Phase 2 Randomized Clinical Trial (GB-SELECT). JAMA Oncol. 2021, 7, 436-439. [CrossRef]

57. Ueno, M.; Morizane, C.; Furukawa, M.; Sakai, D.; Komatsu, Y.; Nakai, Y.; Tsuda, M.; Ozaka, M.; Mizuno, N.; Muto, M.; et al. A randomized, double-blind, phase II study of oral histone deacetylase inhibitor resminostat plus S-1 versus placebo plus S-1 in biliary tract cancers previously treated with gemcitabine plus platinum-based chemotherapy. Cancer Med. 2021, 10, $2088-2099$. [CrossRef] [PubMed]

58. Yoo, C.; Kim, K.P.; Kim, I.; Kang, M.J.; Cheon, J.; Kang, B.W.; Ryu, H.; Jeong, J.H.; Lee, J.S.; Kim, K.W.; et al. Liposomal Irinotecan (nal-IRI) in combination with Fluorouracil (5-FU) and Leucovorin (LV) for Patients (pts) with Metastatic Biliary Tract Cancer (BTC) after Progression on Gemcitabine plus Cisplatin (GemCis): Multicenter Comparative Randomized Phase 2B study (NIFTY). J. Clin. Oncol. 2021, 39 (Suppl. 15), 4006.

59. Nakamura, H.; Arai, Y.; Totoki, Y.; Shirota, T.; Elzawahry, A.; Kato, M.; Hama, N.; Hosoda, F.; Urushidate, T.; Ohashi, S.; et al. Genomic spectra of biliary tract cancer. Nat. Genet. 2015, 47, 1003-1010. [CrossRef]

60. Valle, J.W.; Lamarca, A.; Goyal, L.; Barriuso, J.; Zhu, A.X. New Horizons for Precision Medicine in Biliary Tract Cancers. Cancer Discov. 2017, 7, 943-962. [CrossRef]

61. Jusakul, A.; Cutcutache, I.; Yong, C.H.; Lim, J.Q.; Huang, M.N.; Padmanabhan, N.; Nellore, V.; Kongpetch, S.; Ng, A.W.T.; Ng, L.M.; et al. Whole-Genome and Epigenomic Landscapes of Etiologically Distinct Subtypes of Cholangiocarcinoma. Cancer Discov. 2017, 7, 1116-1135. [CrossRef]

62. Silverman, I.M.; Hollebecque, A.; Friboulet, L.; Owens, S.; Newton, R.C.; Zhen, H.; Féliz, L.; Zecchetto, C.; Melisi, D.; Burn, T.C. Clinicogenomic Analysis of FGFR2-Rearranged Cholangiocarcinoma Identifies Correlates of Response and Mechanisms of Resistance to Pemigatinib. Cancer Discov. 2021, 11, 326-339. [CrossRef] 
63. Javle, M.; Lowery, M.; Shroff, R.T.; Weiss, K.H.; Springfeld, C.; Borad, M.J.; Ramanathan, R.K.; Goyal, L.; Sadeghi, S.; Macarulla, T.; et al. Phase II Study of BGJ398 in Patients With FGFR-Altered Advanced Cholangiocarcinoma. J. Clin. Oncol. 2018, 36, $276-282$. [CrossRef]

64. Mazzaferro, V.; El-Rayes, B.F.; Droz Dit Busset, M.; Cotsoglou, C.; Harris, W.P.; Damjanov, N.; Masi, G.; Rimassa, L.; Personeni, N.; Braiteh, F.; et al. Derazantinib (ARQ 087) in advanced or inoperable FGFR2 gene fusion-positive intrahepatic cholangiocarcinoma. Br. J. Cancer 2019, 120, 165-171. [CrossRef]

65. Abou-Alfa, G.K.; Sahai, V.; Hollebecque, A.; Vaccaro, G.; Melisi, D.; Al-Rajabi, R.; Paulson, A.S.; Borad, M.J.; Gallinson, D.; Murphy, A.G.; et al. Pemigatinib for previously treated, locally advanced or metastatic cholangiocarcinoma: A multicentre, open-label, phase 2 study. Lancet Oncol. 2020, 21, 671-685. [CrossRef]

66. Goyal, L.; Meric-Bernstam, F.; Hollebecque, A.; Morizane, C.; Valle, J.W.; Karasic, T.B.; Abrams, T.A.; Kelley, R.B.; Cassier, P.; Furuse, J.; et al. Primary results of phase 2 FOENIX-CCA2: The irreversible FGFR1-4 inhibitor futibatinib in intrahepatic cholangiocarcinoma (iCCA) with FGFR2 fusions/rearrengements. In Proceedings of the AACR Annual Meeting, Virtual Meeting, Philadelphia, PA, USA, 10-15 April/17-21 May 2021. Abstract CT-010.

67. Maruki, Y.; Morizane, C.; Arai, Y.; Ikeda, M.; Ueno, M.; Ioka, T.; Naganuma, A.; Furukawa, M.; Mizuno, N.; Uwagawa, T.; et al. Molecular detection and clinicopathological characteristics of advanced/recurrent biliary tract carcinomas harboring the FGFR2 rearrangements: A prospective observational study (PRELUDE Study). J. Gastroenterol. 2021, 56, 250-260. [CrossRef]

68. Le, D.T.; Durham, J.N.; Smith, K.N.; Wang, H.; Bartlett, B.R.; Aulakh, L.K.; Lu, S.; Kemberling, H.; Wilt, C.; Luber, B.S.; et al. Mismatch repair deficiency predicts response of solid tumors of PD-1 blockade. Science 2017, 357, 409-413. [CrossRef]

69. Doebele, R.C.; Drilon, A.; Paz-Ares, L.; Siena, S.; Shaw, A.T.; Farago, A.F.; Blakely, C.M.; Seto, T.; Cho, B.C.; Tosi, D.; et al. Entrectinib in patients with advanced or metastatic NTRK fusion-positive solid tumours: Integrated analysis of three phase 1-2 trials. Lancet Oncol. 2020, 21, 271-282. [CrossRef]

70. Drilon, A.; Laetsch, T.W.; Kummar, S.; DuBois, S.G.; Lassen, U.N.; Demetri, G.D.; Natheson, M.; Doebele, R.C.; Fargo, A.F.; Pappo, A.S.; et al. Efficacy of Larotrectinib in TRK Fusion-Positive Cancers in Adults and Children. N. Engl. J. Med. 2018, 378, 731-739. [CrossRef]

71. Akagi, K.; Oki, E.; Taniguchi, H.; Nakatani, K.; Aoki, D.; Kuwata, T.; Yoshino, T. The real-world data on microsatellite instability status in various unresectable or metastatic solid tumors. Cancer Sci. 2021, 112, 1105. [CrossRef] [PubMed]

72. Yoshino, T.; Pentheroudakis, G.; Mishima, S.; Overman, M.J.; Yeh, K.H.; Baba, E.; Naito, Y.; Calvo, F.; Saxena, A.; Chen, L.T.; et al. JSCO-ESMO-ASCO-JSMO-TOS: International expert consensus recommendations for tumour-agnostic treatments in patients with solid tumours with microsatellite instability or NTRK fusions. Ann. Oncol. 2020, 31, 861-872. [CrossRef]

73. Piha-Paul, S.A.; Oh, D.Y.; Ueno, M.; Malka, D.; Chung, H.C.; Nagrial, A.; Kelley, R.K.; Ros, W.; Italiano, A.; Nakagawa, K.; et al. Efficacy and safety of pembrolizumab for the treatment of advanced biliary cancer: Results from the KEYNOTE-158 and KEYNOTE-028 studies. Int. J. Cancer 2020, 147, 2190-2198. [CrossRef]

74. Ueno, M.; Ikeda, M.; Morizane, C.; Kobayashi, S.; Ohno, I.; Kondo, S.; Okano, N.; Kimura, K.; Asada, S.; Namba, Y.; et al. Nivolumab alone or in combination with cisplatin plus gemcitabine in Japanese patients with unresectable or recurrent biliary tract cancer: A non-randomised, multicentre, open-label, phase 1 study. Lancet Gastroenterol. Hepatol. 2019, 4, 611-621.

75. Kim, R.D.; Chung, V.; Alese, O.B.; El-Rayes, B.F.; Li, D.; Al-Toubah, T.E.; Schell, M.J.; Zhou, J.M.; Mahipal, A.; Kim, B.H.; et al. A Phase 2 Multi-institutional Study of Nivolumab for Patients With Advanced Refractory Biliary Tract Cancer. JAMA Oncol. 2020, 6, 888-894. [CrossRef]

76. Feng, K.; Liu, Y.; Zhao, Y.; Yang, Q.; Dong, L.; Liu, J.; Li, X.; Zhao, Z.; Mei, Q.; Han, W. Efficacy and biomarker analysis of nivolumab plus gemcitabine and cisplatin in patients with unresectable or metastatic biliary tract cancers: Results from a phase II study. J. Immunother. Cancer 2020, 8, e000367. [CrossRef] [PubMed]

77. Klein, O.; Kee, D.; Nagrial, A.; Markman, B.; Underhill, C.; Michael, M.; Jackett, L.; Lum, C.; Behren, A.; Palmer, J.; et al. Evaluation of Combination Nivolumab and Ipilimumab Immunotherapy in Patients With Advanced Biliary Tract Cancers: Subgroup Analysis of a Phase 2 Nonrandomized Clinical Trial. JAMA Oncol. 2020, 6, 1405-1409. [CrossRef]

78. Chen, X.; Wu, X.; Wu, H.; Gu, Y.; Shao, Y.; Shao, Q.; Zhu, F.; Li, X.; Qian, X.; Hu, J.; et al. Camrelizumab plus gemcitabine and oxaliplatin (GEMOX) in patients with advanced biliary tract cancer: A single-arm, open-label, phase II trial. J. Immunother. Cancer 2020, 8, e001240. [CrossRef] [PubMed]

79. Villanueva, L.; Lwin, Z.; Chung, H.C.; Gomez-Roca, C.A.; Longo, F.; Yanez, E.; Senellart, H.; Doherty, M.; Garcia-Corbacho, J.; Hendifar, A.E.; et al. Lenvatinib plus pembrolizumab for patients with previously treated biliary tract cancers in the multicohort phase 2 LEAP-005 study. J. Clin. Oncol. 2021, 39 (Suppl. 15), 4080. [CrossRef]

80. Takada, T.; Amano, H.; Yasuda, H.; Nimura, Y.; Matsushiro, T.; Kato, H.; Nagakawa, T.; Nakayama, T.; Study Group of Surgical Adjuvant Therapy for Carcinomas of the Pancreas and Biliary Tract. Is postoperative adjuvant chemotherapy useful for gallbladder carcinoma? A phase III multicenter prospective randomized controlled trial in patients with resected pancreaticobiliary carcinoma. Cancer 2002, 95, 1685-1695.

81. Neoptolemos, J.P.; Moore, M.J.; Cox, T.F.; Valle, J.W.; Palmer, D.H.; McDonald, A.C.; Carter, R.; Tebbutt, N.C.; Dervenis, C.; Smith, D.; et al. Effect of adjuvant chemotherapy with fluorouracil plus folinic acid or gemcitabine vs observation on survival in patients with resected periampullary adenocarcinoma. JAMA 2012, 308, 147-156. [CrossRef] 
82. Ebata, T.; Hirano, S.; Konishi, M.; Uesaka, K.; Tsuchiya, Y.; Ohtsuka, M.; Kaneoka, Y.; Yamamoto, M.; Ambo, Y.; Shimizu, Y.; et al. Randomized clinical trial of adjuvant gemcitabine chemotherapy versus observation in resected bile duct cancer. Br. J. Surg. 2018, 105, 192-202. [CrossRef]

83. Edeline, J.; Benabdelghani, M.; Bertaut, A.; Watelet, J.; Hammel, P.; Joly, J.P.; Boudjema, K.; Fartoux, L.; Bouhier-Leporrier, K.; Jouve, J.L.; et al. Gemcitabine and Oxaliplatin Chemotherapy or Surveillance in Resected Biliary Tract Cancer (PRODIGE 12-ACCORD 18-UNICANCER GI): A Randomized Phase III Study. J. Clin. Oncol. 2019, 37, 658-667. [CrossRef]

84. Primrose, J.N.; Fox, R.P.; Palmer, D.H.; Malik, H.Z.; Prasad, R.; Mirza, D.; Anthony, A.; Corrie, P.; Falk, S.; Finch-Jones, M.; et al. Capecitabine compared with observation in resected biliary tract cancer (BILCAP): A randomized, controlled, multicentre, phase 3 study. Lancet Oncol. 2019, 20, 663-673. [CrossRef]

85. Shroff, R.T.; Kennedy, E.B.; Bachini, M.; Bekaii-Saab, T.; Crane, C.; Edeline, J.; El-Khoueiry, A.; Feng, M.; Katz, M.H.G.; Primrose, J.; et al. Adjuvant Therapy for Resected Biliary Tract Cancer: ASCO Clinical Practice Guideline. J. Clin. Oncol. 2019, 37, 1015-1027. [CrossRef]

86. McNamara, M.G.; Goyal, L.; Doherty, M.; Springfeld, C.; Cosgrove, D.; Sjoquist, K.M.; Park, J.O.; Verdaguer, H.; Braconi, C.; Ross, P.J.; et al. NUC-1031/cisplatin versus gemcitabine/cisplatin in untreated locally advanced/metastatic biliary tract cancer (NuTide:121). Future Oncol. 2020, 16, 1069-1081. [CrossRef]

87. Bekaii-Saab, T.S.; Valle, J.W.; Van Cutsem, E.; Rimassa, L.; Furuse, J.; Ioka, T.; Melisi, D.; Macarulla, T.; Bridgewater, J.; Wasan, H.; et al. FIGHT-302: First-line pemigatinib vs gemcitabine plus cisplatin for advanced cholangiocarcinoma with FGFR2 rearrangements. Future Oncol. 2020, 16, 2385-2399. [CrossRef]

88. Makawita, S.; Abou-Alfa, G.K.; Roychowdhury, S.; Sadeghi, S.; Borbath, I.; Goyal, L.; Cohn, A.; Lamarca, A.; Oh, D.Y.; Macarulla, T.; et al. Infigratinib in patients with advanced cholangiocarcinoma with FGFR2 gene fusions/translocations: The PROOF 301 trial. Future Oncol. 2020, 16, 2375-2384. [CrossRef]

89. Stein, A.; Arnold, D.; Bridgewater, J.; Goldstein, D.; Jensen, L.H.; Klümpen, H.J.; Lohse, A.W.; Nashan, B.; Primrose, J.; Schrum, S.; et al. Adjuvant chemotherapy with gemcitabine and cisplatin compared to observation after curative intent resection of cholangiocarcinoma and muscle invasive gallbladder carcinoma (ACTICCA-1 trial)—A randomized, multidisciplinary, multinational phase III trial. BMC Cancer 2015, 15, 564. [CrossRef]

90. Nakachi, K.; Konishi, M.; Ikeda, M.; Mizusawa, J.; Eba, J.; Okusaka, T.; Ishii, H.; Fukuda, H.; Furuse, J.; Hepatobiliary and Pancreatic Oncology Group of the Japan Clinical Oncology Group. A randomized Phase III trial of adjuvant S-1 therapy vs. observation alone in resected biliary tract cancer: Japan Clinical Oncology Group Study (JCOG1202, ASCOT). Jpn. J. Clin. Oncol. 2018, 48, 392-395. [CrossRef]

91. Goetze, T.O.; Bechstein, W.O.; Bankstahl, U.S.; Keck, T.; Königsrainer, A.; Lang, S.A.; Pauligk, C.; Piso, P.; Vogel, A.; Al-Batran, S.E. Neoadjuvant chemotherapy with gemcitabine plus cisplatin followed by radical liver resection versus immediate radical liver resection alone with or without adjuvant chemotherapy in incidentally detected gallbladder carcinoma after simple cholecystectomy or in front of radical resection of BTC (ICC/ECC) - A phase III study of the German registry of incidental gallbladder carcinoma platform (GR)- the AIO/ CALGP/ ACO- GAIN-trial. BMC Cancer 2020, 20, 122.

92. Shroff, R.T.; Javle, M.M.; Xiao, L.; Kaseb, A.O.; Varadhachary, G.R.; Wolff, R.A.; Raghav, K.P.S.; Iwasaki, M.; Masci, P.; Ramanathan, R.K.; et al. Gemcitabine, Cisplatin, and nab-Paclitaxel for the Treatment of Advanced Biliary Tract Cancers: A Phase 2 Clinical Trial. JAMA Oncol. 2019, 5, 824-830. [CrossRef]

93. Yoo, C.; Oh, D.Y.; Choi, H.J.; Kudo, M.; Ueno, M.; Kondo, S.; Chen, L.T.; Osada, M.; Helwig, C.; Dussault, I.; et al. Phase I study of bintrafusp alfa, a bifunctional fusion protein targeting TGF- $\beta$ and PD-L1, in patients with pretreated biliary tract cancer. J. Immunother. Cancer 2020, 8, e000564. [CrossRef] [PubMed]

94. Boilève, A.; Hilmi, M.; Gougis, P.; Cohen, R.; Rousseau, B.; Blanc, J.F.; Ben Abdelghani, M.; Castanié, H.; Dahan, L.; Tougeron, D.; et al. Triplet combination of durvalumab, tremelimumab, and paclitaxel in biliary tract carcinomas: Safety run-in results of the randomized IMMUNOBIL PRODIGE 57 phase II trial. Eur. J. Cancer 2021, 143, 55-63. [CrossRef] [PubMed] 